\title{
Carbonitriding of low alloy steels: mechanical and metallurgical responses
}

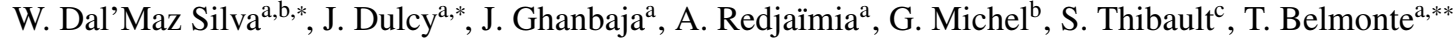 \\ ${ }^{a}$ Institut Jean Lamour - UMR CNRS-Université de Lorraine 7198, Parc de Saurupt, Nancy 54011, France \\ ${ }^{b}$ Institut de Recherche Technologique M2P, Metz 57070, France \\ ${ }^{c}$ Safran Tech, Magny les Hameaux, France
}

\begin{abstract}
Metallurgical and mechanical responses to the introduction of carbon and/or nitrogen have been investigated for alloys 16NiCrMo13 and 23MnCrMo5 through atmospheric pressure carbonitriding, carburizing and austenitic nitriding. Treatments were performed at $1173 \mathrm{~K}$ using $\mathrm{CO}-\mathrm{H}_{2}$ and/or $\mathrm{NH}_{3}$ based atmospheres. As-quenched hardness is studied in terms of solid solution interstitial content, which is estimated from electron probe micro-analyses and thermodynamic simulations. This aims to quantify high-temperature precipitation of nitrides, which is accompanied by consumption of nitrogen in solid solution. Plots of as-quenched hardness versus the square root of the total content expressed in atomic fraction of interstitial elements, i.e. the sum of solution carbon and nitrogen, show the complementary character of these elements in determining the mechanical properties of the as-quenched alloys. Tempering of carbon-nitrogen martensite - for both carbonitriding and austenitic nitriding - led to lower hardness loss when compared to the same total content of interstitial carbon in martensite. Transmission electron microscopy analyses highlight precipitation of fine $\mathrm{Fe}_{16} \mathrm{~N}_{2}$ zones in the nitrogen-rich depth.
\end{abstract}

Keywords: hardness measurement, martensite, steel, precipitation

\section{Introduction}

Carbonitriding is an austenitic field case hardening process generally conducted from $1073 \mathrm{~K}$ to $1173 \mathrm{~K}[1$. 2] through the introduction of carbon and nitrogen into iron, low-carbon low-alloy steels and powder metallurgy parts. It is often performed on power transmission parts, such as gears, which are submitted to structural and surface fatigue operating conditions. Aiming at the required properties, carbonitrided parts are quenched [3] to outcome the strain energy required by martensite transformation [4]. This leads to a hard and brittle lath martensite microstructure, which is typically tempered prior to application. Thus, the understanding of attainable mechanical properties is based on carbon-

\footnotetext{
${ }^{*}$ Corresponding author

** Principal corresponding author

Email addresses:

walter.dal-maz-silva@univ-lorraine.fr (W. Dal'Maz Silva), jacky.dulcy@univ-lorraine.fr (J. Dulcy), jaafar.ghanbaja@univ-lorraine.fr (J. Ghanbaja), abdelkrim.redjaimia@univ-lorraine.fr (A. Redjaïmia), gregory.michel@irt-m2p.fr(G. Michel), simon.thibault@safran.fr (S. Thibault), thierry.belmonte@univ-lorraine.fr (T. Belmonte)
}

nitrogen martensite behavior. Conversely to nitrogen effects [5, 6], much has been reported about the role of carbon on martensite transformation of steels [7]. For nitrogen martensite, literature remains mostly limited to the Fe-N system, for which metallurgical transformations through tempering and room temperature aging are established [8-15]. Although the as-quenched behavior of carbon martensite can be readily described in terms of interstitial content [7, 16-18], nitrogen effects are not often reported. It has been proposed that for typical treatment durations, precipitation of nitrides does not reach the equilibrium fractions computed with some of the currently available thermodynamic databases [5]. Thus, elemental partitioning [19] between matrix and nitrides formed during alloy enrichment plays a role on the nature and fractions of possible phases formed during tempering, leading to a series of more complex mechanisms which will be discussed throughout the text. Intending to explore metallurgical responses rather than process parameters, which may be found in reference papers [1, 20], this work focuses on carbonitriding as a sequence of carburizing and nitriding steps, even though simultaneous enrichment in both interstitial elements is the long-term established industrial practice 
of atmospheric process. Nitrogen solubility at treatment temperature is drastically reduced by the presence of alloying elements such as chromium and manganese and precipitation of nitrides takes place already during enrichment. Thus, the effective nitrogen hardening effect is linked to the reminiscent interstitial nitrogen, which also reduces the critical cooling rate for quenching, leading to a more consistent martensite transformation. Experimental studies supported by Thermo-Calc [21] thermodynamic simulations of steels composition after treatments were conducted. Hardening responses to carburizing and austenitic nitriding are compared to carbonitriding results. Diffusion profiles are correlated with local hardness and microstructure. Dictra [21, 22] simulations are used for predicting $\mathrm{MN}$-nitrides precipitation along the diffusion profile, thus, incorporating nitrogen in the as-quenched hardness model [16, 17].

\section{Experimental methods}

\subsection{Treatment parameters}

Metallurgical responses to thermochemical treatments - carburizing, austenitic nitriding and carbonitriding - of alloys given in Tab. 1 are studied. Specimens with dimensions of $40 \mathrm{~mm} \times 14 \mathrm{~mm} \times 4 \mathrm{~mm}$ taken from wrought bars are polished up to 1200 grit sandpaper prior to enrichment. Processing is then carried out in a vertical flow reactor with diameter of $50 \mathrm{~mm}$ and $100 \mathrm{~mm}$ isothermal length at the setup temperature. Since the studied alloys do not contain intentionally added grain growth stabilizers, in order to optimize process kinetics without compromising austenitic grain size [23], a temperature of $1173 \mathrm{~K}$ is adopted for all treatments. Heating is carried out under inert atmosphere consisting of $\mathrm{N}_{2}-0.2 \mathrm{H}_{2}$ with total flow rate of $500 \mathrm{~cm}^{3} \mathrm{~min}^{-1}$. A carburizing atmosphere based on $\mathrm{CO}-\mathrm{H}_{2}$, controlled through dew point measurement [24], has been designed to promote carbon surface saturation. Nitrogen enrichment is conducted through an ammonia/cracked ammonia atmosphere. Diffusion steps as well as tempering times and temperatures are given in Tab. 2. After treatment, samples are immediately oil quenched $(298 \mathrm{~K})$ and submitted to cryogenic treatment in boiling nitrogen $(77 \mathrm{~K})$. Tempering is then conducted under the same atmosphere employed during heating stage.

\subsection{Materials characterization}

Treated samples are cross-sectioned and epoxy resin hot mounted prior to analysis. Grinding is followed by progressive alumina polishing until particle size below
Table 1: Nominal composition of the studied alloys (wt.\%).

\begin{tabular}{cccccccc}
\hline Alloy & $\mathrm{Fe}$ & $\mathrm{C}$ & $\mathrm{Si}$ & $\mathrm{Mn}$ & $\mathrm{Cr}$ & $\mathrm{Ni}$ & $\mathrm{Mo}$ \\
\hline 16NiCrMo13 & bal. & 0.16 & 0.25 & 0.45 & 1.00 & 3.20 & 0.25 \\
23MnCrMo5 & bal. & 0.23 & 0.25 & 1.20 & 1.30 & 0.20 & 0.25 \\
\hline
\end{tabular}

$0.5 \mu \mathrm{m}$. Visible-light microscopy (VLM) assessment of microstructure and mechanical property measurement through Vickers micro-hardness testing under a load of $300 \mathrm{gf}$ (HV0.3) are carried out. Chemical microanalyses of diffusion profiles are conducted through Jeol JXA-8530F electron probe micro analyzer (EPMA) using the same calibration techniques described by Catteau et al. [5]. Identification of both high and low temperature precipitates, i.e. those formed during enrichment and those formed during temper, respectively, is realized through transmission electron microscopy (TEM) using a Jeol ARM-200F equipment operating at $200 \mathrm{kV}$. High temperature precipitates composition and distributions are identified semi-quantitatively by energy dispersion x-ray spectroscopy (EDS). Precipitates structure is identified by electron diffraction.

\section{Results}

Effects of cryogenic treatment over retained austenite $\left(\gamma_{r}\right)$ decomposition after carbonitriding of alloy 16NiCrMo13 are presented in Fig. 1. showing equivalent regions before and after cryogenic treatment along with local composition. This representation is proposed in order to provide understanding of $\gamma_{r}$ content in terms of interstitial elements mass fractions and will later be related to the H-point composition [15]. Quantification by VLM image analysis in the cross-section gives a fraction of $\gamma_{r}$ around $35 \%$ in the region comprised between the surface and a depth of $200 \mu \mathrm{m}$. Figure 3 summarizes measured as well as simulated diffusion profiles for all treatment setups. Under the same operating conditions, i.e. same nitriding potential [25], surface nitrogen for alloy $16 \mathrm{NiCrMo} 13$ did not reach 0.4 wt. $\% \mathrm{~N}$ while alloy $23 \mathrm{MnCrMo} 5$ exceeds $0.6 \mathrm{wt} . \%$ N. Carbonitrided samples of both materials show the same carbon profile shape but with reasonably lower surface content than the simulated values. A similar surface carbon decrease is observed in nitrided samples, remarkably for alloy $23 \mathrm{MnCrMo5}$ due to its higher initial content, without any accumulation peak toward the core. Experimental composition profiles are then used as input for local equilibrium computations at enrichment temperatures using Thermo-Calc [21] database TCFE7. Such simulations provide the total solid solu- 
Table 2: Treatment durations for carburizing, austenitic nitriding and carbonitriding.

\begin{tabular}{|c|c|c|c|c|c|}
\hline \multirow{2}{*}{ Treatment } & \multirow{2}{*}{ Material } & \multicolumn{3}{|c|}{ Enrichment/diffusion duration at $1173 \mathrm{~K}$} & \multirow{2}{*}{$\begin{array}{c}\text { Tempering }{ }^{a} \\
\left(\mathrm{~N}_{2}-\mathrm{H}_{2}\right)\end{array}$} \\
\hline & & $\begin{array}{c}\text { Carbon } \\
\left(\mathrm{CO}-\mathrm{H}_{2}-\mathrm{N}_{2}\right)\end{array}$ & Diffusion & $\begin{array}{c}\text { Nitrogen } \\
\left(\mathrm{NH}_{3}-\mathrm{H}_{2}-\mathrm{N}_{2}\right)\end{array}$ & \\
\hline \multirow{2}{*}{ Carburizing } & 16NiCrMo13 & \multirow{2}{*}{$2 \mathrm{~h}$} & $4 \mathrm{~h}$ & \multirow[t]{2}{*}{-} & \multirow{4}{*}{$\begin{array}{l}70 \mathrm{~h} \text { at } 453 \mathrm{~K} \\
18 \mathrm{~h} \text { at } 573 \mathrm{~K}\end{array}$} \\
\hline & 23MnCrMo5 & & $3 \mathrm{~h}$ & & \\
\hline Nitriding & both & - & - & $3 \mathrm{~h}$ & \\
\hline Carbonitriding & $\begin{array}{l}\text { 16NiCrMo13 } \\
\text { 23MnCrMo5 }\end{array}$ & $2 \mathrm{~h}$ & $\begin{array}{l}1 \mathrm{~h} \\
-\end{array}$ & $3 \mathrm{~h}$ & \\
\hline
\end{tabular}

${ }^{a}$ Nitrided samples were also tempered during $18 \mathrm{~h}$ at $673 \mathrm{~K}$.

tion atomic fraction $x_{i}$ for carbon and nitrogen, which is then used to plot hardness - in the as-quenched and after cryogenic treatment conditions - versus $x_{i}^{0.5}$, the square root of this quantity, as shown in Fig. 4 This method makes no distinction between treatments since it is resorted to evidence the complementary character of interstitial elements. Three distinct behaviors are depicted in Fig. 4. (i) a linear dependence of hardness with $x_{i}$ up to a value of 0.16 (corresponding to around 0.550.60 wt. \% of interstitials) which is followed by (ii) a hardening plateau until around 0.19 (0.90 wt.\% of interstitials) and then (iii) a strong hardness decrease for higher contents. These points beyond the so-called Hpoint were obtained from high carbon samples, which were quenched directly after enrichment for illustration purposes and correspond to the microstructure presented in Fig. 1. Next, Fig. 5 shows the tempering behavior of the cryogenic quenched samples with diffusion profiles given in Fig. 3- except for nitrided samples, which are discussed apart. For alloy 16NiCrMo13 the maximum hardness attained by cryogenic quenching was around $750 \mathrm{HV} 0.3$ while for alloy $23 \mathrm{MnCrMo}$, hardening reached $800 \mathrm{HV} 0.3$. These start-points are presented together with hardness profiles for samples tempered at both $453 \mathrm{~K}$ and $573 \mathrm{~K}$. Hardness profiles for nitrided samples are presented in Fig. 6 to better depict the abnormal tempering effect observed for this treatment: hardness is kept close to the as-quenched level in the nitrogen-rich zone if tempering is carried out above $573 \mathrm{~K}$, while at $453 \mathrm{~K}$ hardness decreases as a whole. The reported mechanical responses are then studied by transmission electron microscopy. Figure 7 presents chemical maps of sub-micrometric precipitates observed in a foil taken at $0.2 \mathrm{~mm}$ from the treated surface of alloy $23 \mathrm{MnCrMo5}$ after carbonitriding. These maps present the main elements found to compose the precipitates, which include nitrogen, chromium, manganese and silicon. On the other hand, precipitates formed at enrichment temperatures during nitriding and carbonitriding for alloy $16 \mathrm{NiCrMo} 13$ show only significant amounts of nitrogen and chromium (Fig. 8). Finally, the abnormal behavior observed after tempering nitrided specimens of alloy $16 \mathrm{NiCrMo} 13$ is depicted in Fig. 6. It is studied by comparing the reference asquenched state microstructure (Fig. 9) with the sample tempered at $573 \mathrm{~K}$ (Fig. 10), comprising standard transmission micrographs, diffraction patterns (DP) and high resolution microscopy (HRTEM). Although both Fig. $9 \mathrm{~d}$ and Fig. $10 \mathrm{p}$ present similar diffraction patterns corresponding to $\mathrm{Fe}_{16} \mathrm{~N}_{2}$ precipitates, different sizes and morphologies are observed.

\section{Discussion}

Before proceeding with the analyses of diffusion profiles and their influence over mechanical properties, some knowledge about the equilibrium phases at enrichment temperature $(1173 \mathrm{~K})$ is desirable. ThermoCalc [21] was used for the simulation of pseudoequilibrium isothermal sections in terms of carbon and nitrogen contents. Using database TCFE7, carbon saturation at $\sim 1.0 \mathrm{wt} . \%$ is predicted for both alloys, above which $\mathrm{M}_{3} \mathrm{C}$ is the equilibrium carbide, as reported for some of the ternary and quaternary systems closely related to the studied alloys [26-28]. The threshold for precipitation of nitrides is found around $0.10 \mathrm{wt} . \% \mathrm{~N}$ in the absence of carbon and decreased slightly to 0.08 wt. $\% \mathrm{~N}$ at carbon saturation. Since these computations are performed considering all the elements listed in Tab. 1, diagrams tie-lines are not in the calculation plane and thus, these limits for precipitation of carbides and nitrides are just thresholds above which further solubility of interstitials is still possible. To illustrate this, Fig. 2 presents the content of nitrogen in solid solution along with MN nitride volume fraction in terms of total nitrogen content. Increasing the nitrogen content above 

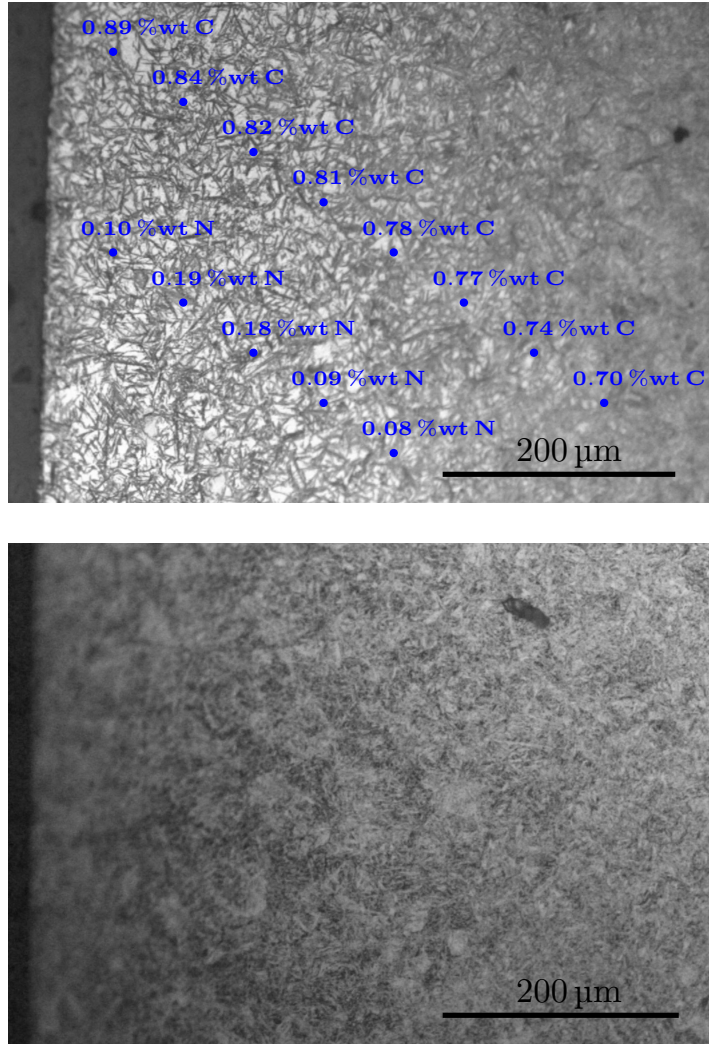

Figure 1: Visible light micrographs of alloy $16 \mathrm{NiCrMo13}$, surface enriched with around $0.90 \mathrm{wt} . \% \mathrm{C}$ and $0.10 \mathrm{wt} . \% \mathrm{~N}$, after (a) oil quench and (b) cryogenic treatment. Local composition along the profile is shown in figure. Magnification of $200 \times$.

the precipitation threshold leads to increasing the nitrogen solubility: the alloy behavior approaches the ironlike solubility limit due to the depletion of alloying elements from the matrix. Simulations show that up to a certain limit (below $0.5 \mathrm{wt} . \% \mathrm{~N}$ in the range of carbon contents achieved in the present work), only MN $(\mathrm{M}=\mathrm{Cr}, \mathrm{Mo})$ nitrides are present, while higher contents lead to the precipitation of $\mathrm{Si}_{3} \mathrm{~N}_{4}$, as expected in the iron-rich corner for the Fe-Si-N system [29]. Precipitation is accompanied by the depletion of alloying elements from the matrix, leading to increased nitrogen solubility, i.e. the austenitic matrix tends towards the Fe-N system behavior. Due to their size - submicrometer scale - and morphology kinetically favored by treatment temperature, these nitrides are incoherent with the matrix and do not represent a dislocation glide barrier.

\subsection{Diffusion profiles}

Figure 3 presents the intricate behavior of carbon and nitrogen diffusing simultaneously during carbonitriding

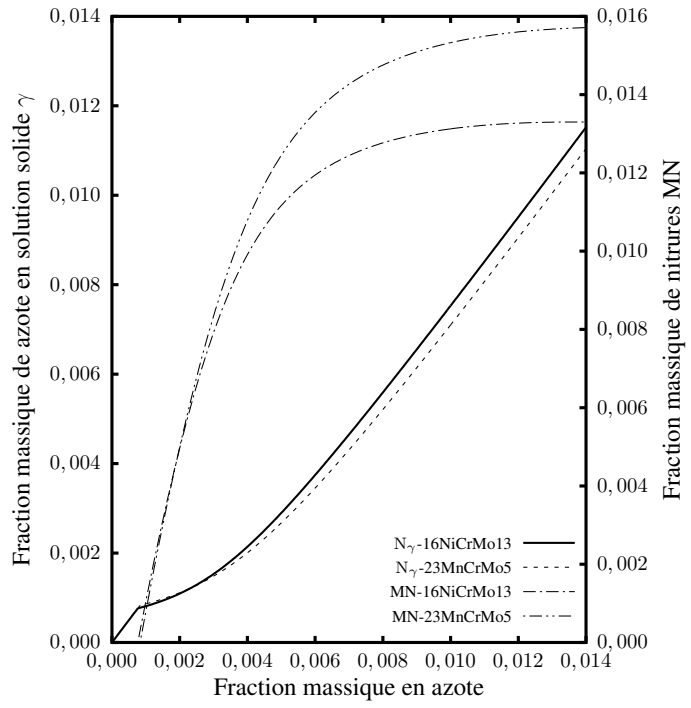

Figure 2: Content of nitrogen in solid solution and volume fraction of nitrides in terms of total nitrogen content for alloys $16 \mathrm{NiCrMo} 13$ and $23 \mathrm{MnCrMo5}$. Simulations were carried out with Thermo-Calc, database TCFE7.

and austenitic nitriding when compared with the singlephase diffusion of carbon during carburizing. Processing conditions led to diffusion profiles in good agreement with Dictra [21, 22] simulations for carburizing. On the other hand, carbonitriding is not properly modeled simply by constant surface activity boundary conditions derived from atmosphere thermodynamics, i.e. saturation activity for carbon and atmosphere nitrogen activity. The carbon maximum observed for both alloys in the carbonitriding simulations around $0.3 \mathrm{~mm}$ from the surface is mostly related to repulsion of interstitial elements between themselves, i.e. carbon-carbon, nitrogen-nitrogen and nitrogen-carbon negative interacting energies, but also by the precipitation of nitrides during enrichment and de-carburizing during nitriding, evidenced by gas chromatography with the formation of methane. Based on the measurement of this hydrocarbon output, surface reaction rate is estimated and implemented as boundary condition for carbon back-flow in order to properly simulate carbonitriding diffusion profiles. Carbon-carbon repulsion behavior is well known and reported in the literature [30-33]. In order to allow the simulation of such phenomenon and the interactions between alloying elements and interstitials, Onsager [34, 35] linear approach for irreversible thermodynamics is taken into account by Dictra [21, 22]. Reasonably similar results may be achieved by integrating the time-dependent diffusion equation following the ap- 
proach given by Slycke and Ericsson [2] for the Fe-C$\mathrm{N}$ system. This approach takes into account the dependencies of the diffusion coefficients with interstitial contents only through a geometric exclusion formalism. This implies that for low alloy steels, interaction energies amongst interstitials are much higher than with alloying elements, which play a major role only on blocking diffusion by formation of precipitates. Using the composition-independent carbon diffusion coefficient in austenite supplied by Slycke and Ericsson [2], it can be shown, for instance, with a Crank-Nicolson [36] scheme solution of the diffusion equation, that the preexponential factor needs to be multiplied by a factor of 1.8-2.0 in order to produce the same mass intake as Dictra [21, 22] simulated values. This is in agreement with a discussion by Bhadeshia [30]. It means that C-C interactions can almost double the carbon diffusion coefficient with respect to its infinite dilution limit, i.e. in absence of carbon.

Measurements of residual ammonia at reactor outlet allow the computation of nitrogen activity around value $a_{N}=40$, by taking atmospheric pressure $\mathrm{N}_{2}$ as the reference state and equilibrium expressions given by Slycke and Ericsson [1]. This value was initially used for establishing the boundary condition for nitriding steps simulations, reasonably representing nitrogen profiles for alloy $23 \mathrm{MnCrMo5}$. Regarding alloy $16 \mathrm{NiCrMo13}$, this activity does not allow proper simulation of diffusion profiles, which are best fit by a nitrogen activity in the order of 10. This is probably due to the catalytic effect of nickel favoring the recombination of adsorbed nitrogen atoms and formation of $\mathrm{N}_{2}$ or other gas phase products. Due to this deviation, nitrogen in solid solution is computed from the actual measured total nitrogen content in order to be incorporated in the hardening model.

\subsection{As-quenched hardness}

Hardness profiles of as-quenched martensite presented in Fig. 5]agree with typical reported values [7, 18, 37, 38] for plain iron and low-alloy steels. Although this property is dependent on several factors such as martensite morphology, solid solution hardening and dislocation density and mobility [7], its strongest dependence lays on interstitial content, allowing direct comparison amongst iron-based materials [18, 37]. For instance, Hutchinson et al. [18] show that for Fe-1.7Mn-0.23Si$0.12 \mathrm{C}$ and $\mathrm{Fe}-1.7 \mathrm{Mn}-0.21 \mathrm{Cr}-0.23 \mathrm{Si}-0.23 \mathrm{C}$ steels, the contribution of base alloying elements represents 10$12 \%$ of the yield strength, while grain size corresponds to about $13 \%$, dislocations to $12-13 \%$, martensite structure to $35-39 \%$ and interstitial atoms to $61-66 \%$. It is assumed that the authors [18] reasoning was based on

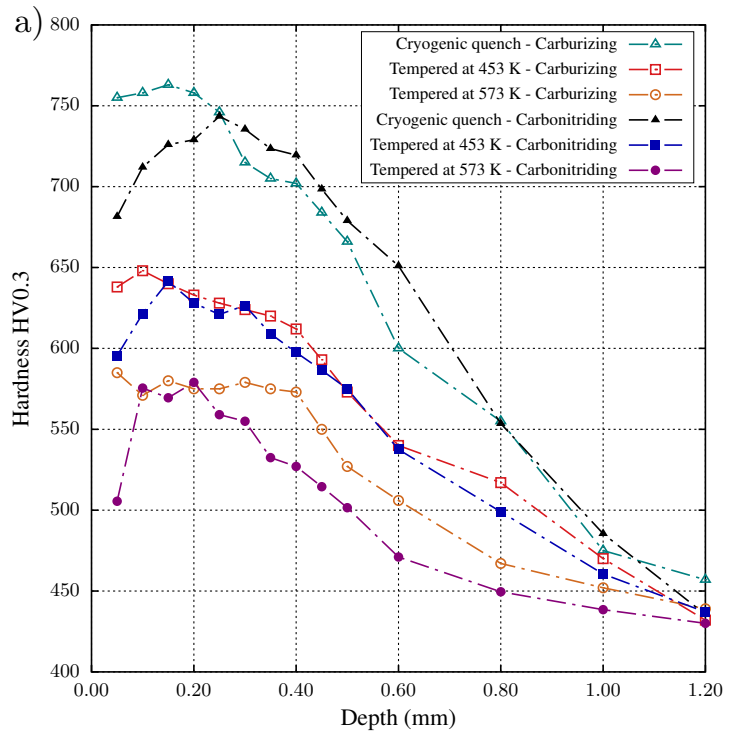

b)

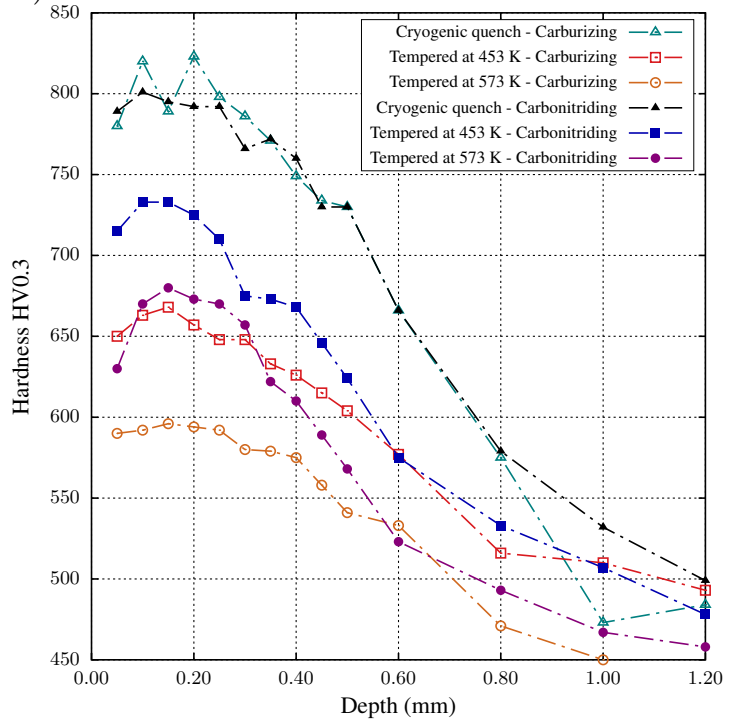

Figure 3: Carbon and nitrogen diffusion profiles: (a) alloy16NiCrMo13 and (b) alloy $23 \mathrm{MnCrMo5}$. Full lines with same color as dotted lines represent the simulated profiles. Simulations were carried out with Dictra, databases TCFE7 and MOBFE2. 
the idea that interstitial atoms behave as if they were solid solution clusters, blocking dislocation movement thanks to precipitates, and thus contributing to strengthening by a square-root dependence on their content [39]. Results by Morito et al. [40] show a linear dependence of dislocation density on carbon content. Since dislocation forest strengthening is also represented by a square-root law versus dislocation density, this term in the total strengthening also obeys a square-root dependence with interstitial content [7, 16-18]. We speculate that a similar behavior may be attributed to nitrogen in solid solution below what is known as the H-point, i.e. the composition at which BCC to BCT martensite transition occurs, accompanied by retention of austenite, since it happens at the same atomic fraction for both carbon and nitrogen [15]. Thus, the relationship proposed by Norstrom [17] may be generalized by considering the total mole fraction xi of solid solution carbon and nitrogen, i.e. the amounts of these elements that are not under the form of precipitates. These assumptions made, the knowledge of actual nitrogen in solid solution is necessary so that this element may be introduced in the model. Thermo-Calc [21] was used in the computation of the total interstitial mole fraction at each point where chemical microanalysis has been performed. Other contributions, such as depletion of alloying elements from the matrix or changes in martensite structure were considered irrelevant based on the discussion above. Figure 4 presents the plot of hardness versus $x_{i}^{0.5}$. Such behavior for both elements seems logical if we consider the dislocation blocking in terms of clusters of interstitials, which must increase with the relative number of interstitial atoms in the structure, since the number of barriers to dislocation movement is the actual variable governing hardness [39]. Furthermore, as depicted by Yahia [41], the size of nitrogen in austenite is only about of 5-7\% larger than carbon, thus, on the average it is expected a close blocking effect for both elements. An exhaustive study could possibly allow the introduction of a coefficient for relative nitrogen effect, thus refining this model. Two main regions characterize plots in Fig. 4. the first for which hardness increases linearly with increasing parameter $x_{i}^{0.5}$ followed by hardening plateau. A straight line is added in order to highlight the zone where proportionality prevails, which has its upper boundary at $x_{i}^{0.5}=0.16$ before cryogenic treatment. This value may roughly be converted to $w_{C}+w_{N}=0.0055$ (0.55 wt.\%), above which no surface improvement may be achieved with room temperature oil-quench, corresponding to the well-known H-point [15]. A third zone may be considered for highly enriched zones (above $x_{i}^{0.5}=0.18$ )

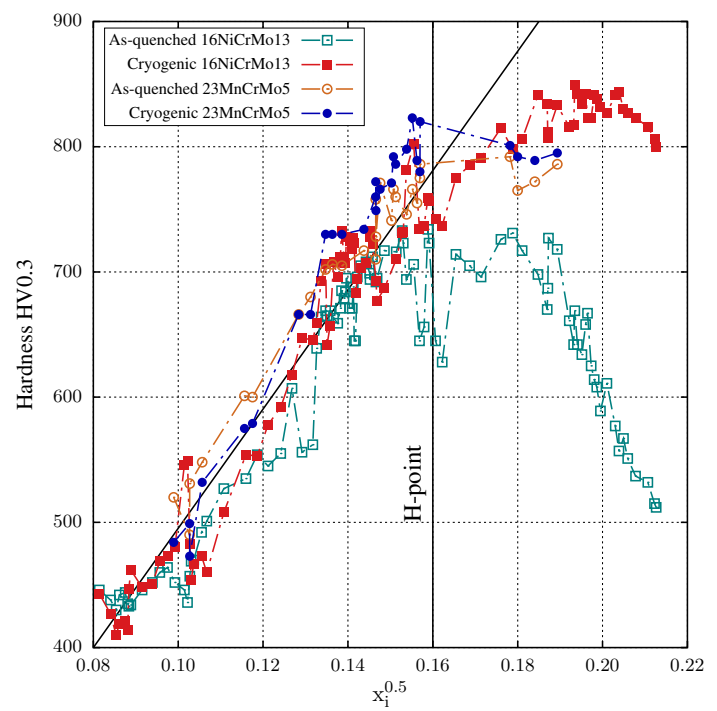

Figure 4: Validity of adopted hardening model below the H-point for alloys $16 \mathrm{NiCrMo} 13$ and $23 \mathrm{MnCrMo5}$.

at which hardness drastically decreases due to the fast growth in the amount of $\gamma_{r}$ [15]. The decomposition of $\gamma_{r}$ with cryogenic treatment is brought to light for alloy $16 \mathrm{NiCrMo13}$ in Fig. 4 by the increase in hardness produced by its transformation into martensite. No such phenomenon has been observed for alloy 23MnCrMo5 since it has not been enriched to high levels of interstitials.

\subsection{Tempering effects}

While the as-quenched hardness may be explained in terms of interstitial content, tempering produces a series of more complex phenomena leading to hardness decrease, as depicted in Fig. 5 where hardness after cryogenic treatment is chosen as reference state. Hardness drop is lower for carbonitriding than for carburizing in the nitrogen rich depth, this effect being fairly more pronounced for alloy $23 \mathrm{MnCrMo} 5$ for both temper conditions. Although the starting points for the treatments were identical (around $800 \mathrm{HV} 0.3$ close to the surface), carbonitriding profiles produced hardness about 70 HV0.3 higher in the nitrogen-rich depth than carburizing alone for alloy $23 \mathrm{MnCrMo5}$. Alloy $23 \mathrm{Mn}-$ CrMo5 has been enriched up to around $0.8 \mathrm{wt} \% \mathrm{~N}$ close to the surface, what under equilibrium conditions should decrease the amount of solid solution chromium by less than $0.3 \mathrm{wt} . \%$ if one considers only the formation of $\mathrm{MN}$ nitrides. One might also expect lower martensite stability in agreement with the results by Grange et al. [37]. If we consider the precipitation of $\mathrm{MnSiN}_{2}$ [5, 6] 
also depleting the matrix from manganese, martensite becomes even more unstable. As per Catteau et al. [5], although equilibrium is not reached under the current experimental conditions, it is not far. Thus, tempering is governed by an iron-like matrix, for which the formation of incoherent $\mathrm{Fe}_{16} \mathrm{~N}_{2}$ is expected [8-14]. Nonetheless, this precipitates are known to lead to a maximum hardening during room temperature aging and lead to a hardness drop during tempering. It is proposed that the reminiscent alloying elements retard such coherent-toincoherent transformation of $\mathrm{Fe}_{16} \mathrm{~N}_{2}$ observed in plain iron [42]. Furthermore, it must be emphasized that the equilibrium nitride under these conditions, $\mathrm{Fe}_{4} \mathrm{~N}$, has not been observed, supporting to the aforementioned model.

\subsection{Austenitic nitriding}

Austenitic nitriding led to a different behavior when compared to both carburizing and carbonitriding. While the introduction of only carbon or a combination of carbon and nitrogen led to hardness decrease in the whole profile after temper, nitrided samples tend to maintain hardness close to the as-quenched state in the nitrogen rich layer if tempering is carried above a certain temperature. Even though the hold time was shorter for higher temperatures (Tab. 2), and according to $\mathrm{H}$ parameter giving time-temperature relations for tempering (Hollomon-Jaffe constant assumed equal to 20 [3, 43]), stress relief with hardness drop along the profiles for all conditions was expected with increasing temperature, in contrast with experimental observations. Increasing tempering temperature to $673 \mathrm{~K}$ also maintains the hardness at the same level (Fig. 6). It is accompanied by the displacement of the hardness maximum toward the core and the hardness loss is more pronounced beyond nitrogen reach, such as depicted in Fig. 6, what is given by the increased nitrogen mobility and possible coalescence of precipitates at this temperature. These results imply a secondary precipitation happening during temper, which counterbalances hardness loss due to the relief of internal stress. It is important to emphasize that hardness decrease is steeper for higher temperatures in zones beyond nitrogen reach, controlled by tempering of carbon-based martensite and confirming the hypothesis of precipitation during temper. This behavior may justify the improved hardness retention of carbonitriding over carburizing.

\subsection{Transmission electron microscopy}

Transmission electron microscopy studies revealed the martensite structure for different treatment condi-
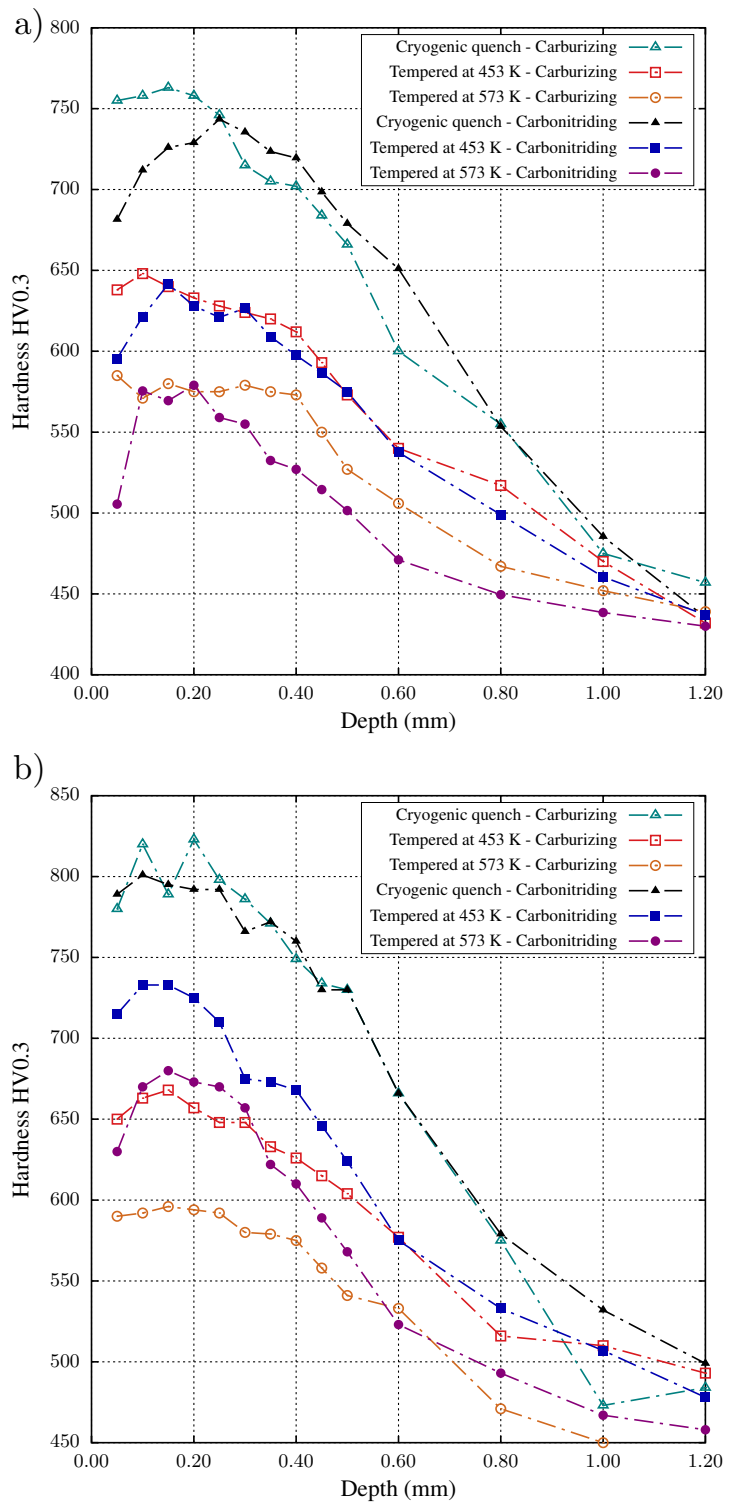

Figure 5: Hardness profiles after oil quenching, cryogenic treatment and tempering for alloys (a) 16NiCrMo13 and (b) 23MnCrMo5. 


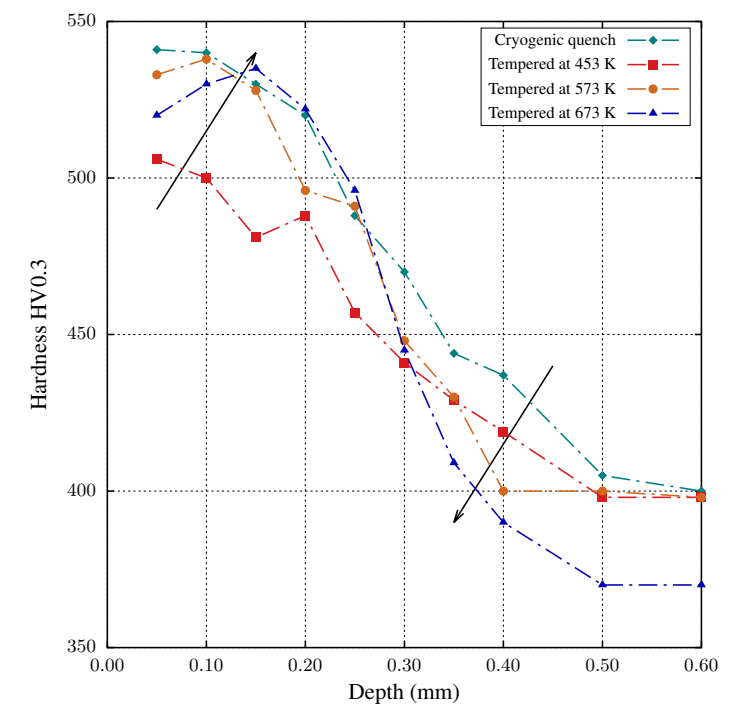

Figure 6: Micro-hardness profiles after cryogenic treatment and different tempering conditions for alloy $16 \mathrm{NiCrMo} 13$ nitrided.

tions and stages. Focus has been given on elemental redistribution due to the formation of high temperature nitrides. Austenitic nitriding of alloy 16NiCrMo13 led (Fig. 9) to a lath martensite structure with a typical lath width of $200 \mathrm{~nm}$ to $500 \mathrm{~nm}$ in a region containing about 0.13 wt. $\% \mathrm{C}$ and around 0.25 wt. $\% \mathrm{~N}$ after quenching and cryogenic treatment. Small amounts of homogeneously distributed sub-micron precipitates formed at enrichment temperature are evidenced by the contrast in these images and confirmed to be MN nitrides - where $\mathrm{M}$ is basically $\mathrm{Cr}$ - through the chemical cartographies presented in Fig. 8. Globular as well as stud-like morphologies of MN precipitates were evidenced to cover around $1.8-2.5 \%$ of the foils crosssections while Thermo-Calc [21] predicts a volume fraction of $1.0 \%$ for the local composition. Once the areas from where chemical cartographies were taken have an average thickness of $80 \mathrm{~nm}$ and by assuming that all MN precipitates in the scanned volume are detected, a rough estimate of the volume fraction of this component around 0.8-1.0\% can be obtained from image analyses, close enough to the predicted value and thus local equilibrium. This result provides validation to the assumptions made previously for the analysis of as-quenched hardness. The material presents shearing zones of around $100 \mathrm{~nm} \times 10 \mathrm{~nm}$ (Fig. 9k) composed of $\mathrm{Fe}_{16} \mathrm{~N}_{2}$ as identified by diffraction pattern shown in Fig. 9d. Analysis of Fig. 6 provided a base line to the study of tempered samples. For samples tempered at $573 \mathrm{~K}$ and above, homogeneous precipitation of a multitude of small - less then $5 \mathrm{~nm} \mathrm{Fe}{ }_{16} \mathrm{~N}_{2}$ particles in the BCC martensite matrix has been detected. These particles could explain the abnormal tempering behavior depicted in Fig. 6, given their size and coherence with the matrix. It is proposed that the depleted alloy matrix behaves as pure $\mathrm{Fe}$ but with retarded precipitation of $\mathrm{Fe}_{16} \mathrm{~N}_{2}$, leading to the observed behavior. This could be linked to a mass action kinetic limitation due to low nitrogen content, which did not allow the precipitates to reach the stable Fe4N observed for a much higher nitrogen mass fraction even at $433 \mathrm{~K}$ by Kaplow et al. [8]. For as-quenched alloy 23MnCrMo5 containing $0.35 \mathrm{wt} . \% \mathrm{C}$ and $0.80 \mathrm{wt} . \% \mathrm{~N}$, contrast and chemical maps brought to light a higher amount of high temperature precipitates than for alloy $16 \mathrm{NiCrMo5}$, as expected. These may be classified into spherical/ellipsoidal and cuboid morphologies, such as depicted by the chemical maps shown in Fig. 8. These nitrides have already been reported by Catteau et al. [6], evidencing the precipitation of $\mathrm{MN}$ nitrides at grain boundaries of previous austenite and also homogeneously distributed in the matrix of alloy $23 \mathrm{MnCrMo5}$, but no $\mathrm{Si}_{3} \mathrm{~N}_{4}$ (as predicted by Thermo-Calc [21], database TCFE7) has been found either in the present work or in Catteau et al. [6]. The authors [6] also report the presence of $\mathrm{VN}$, not identified in the present work, and $\mathrm{MnSiN}_{2}$ (space group $P n a 2_{1}$ [29]) formed at relatively lower nitrogen contents with regards to the present work such as $0.25 \mathrm{wt} . \%$. The presence of $\mathrm{MnSiN}_{2}$ is confirmed in the present study but not predicted by thermodynamic calculations with the used database.

\section{Conclusions}

The present work showed that the hardening achieved through carbonitriding of low alloy steels may be predicted in terms of Norstrom [17] model if interstitial atoms are taken into account by mole fractions, allowing the inclusion of nitrogen in order to explain the as-quenched hardness. The use of computational thermodynamics software allowed the estimation of these quantities in austenite, which were considered relevant to martensite composition. The maximum hardening seems also related to the BCC to BCT structural transformation of martensite, being reflected to a total mass fraction of solid solution interstitials of $0.55 \mathrm{wt} \%$, the known H-point [15]. Tempering led to a less pronounced hardness drop for carbonitriding than carburizing, evidencing a secondary precipitation mechanism. This result is also seen from austenitic nitriding, for which a minimum temperature for such precipitation was inferred. Transmission electron microscopy 

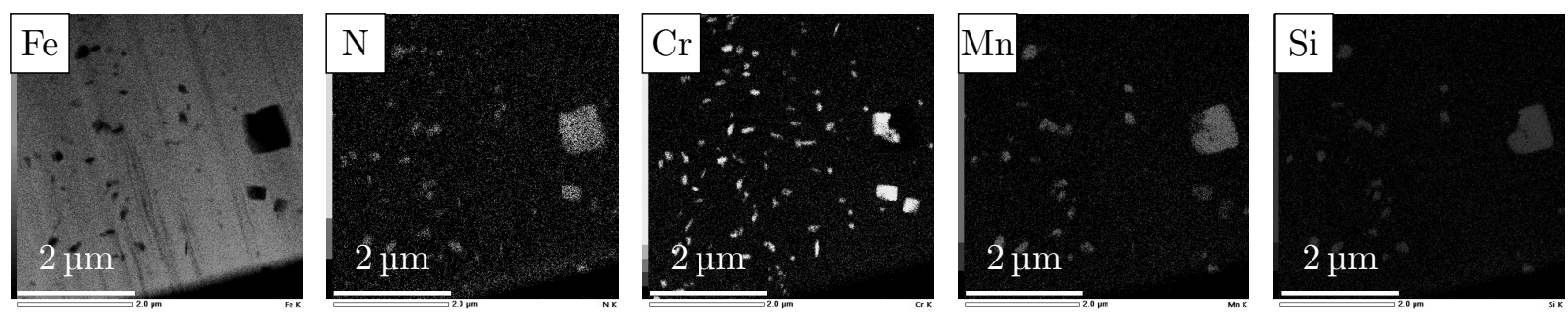

Figure 7: Energy dispersive x-ray maps of nitrides formed during carbonitriding of alloy $23 \mathrm{MnCrMo5}$. Nitrogen content around 0.80 wt.\%.
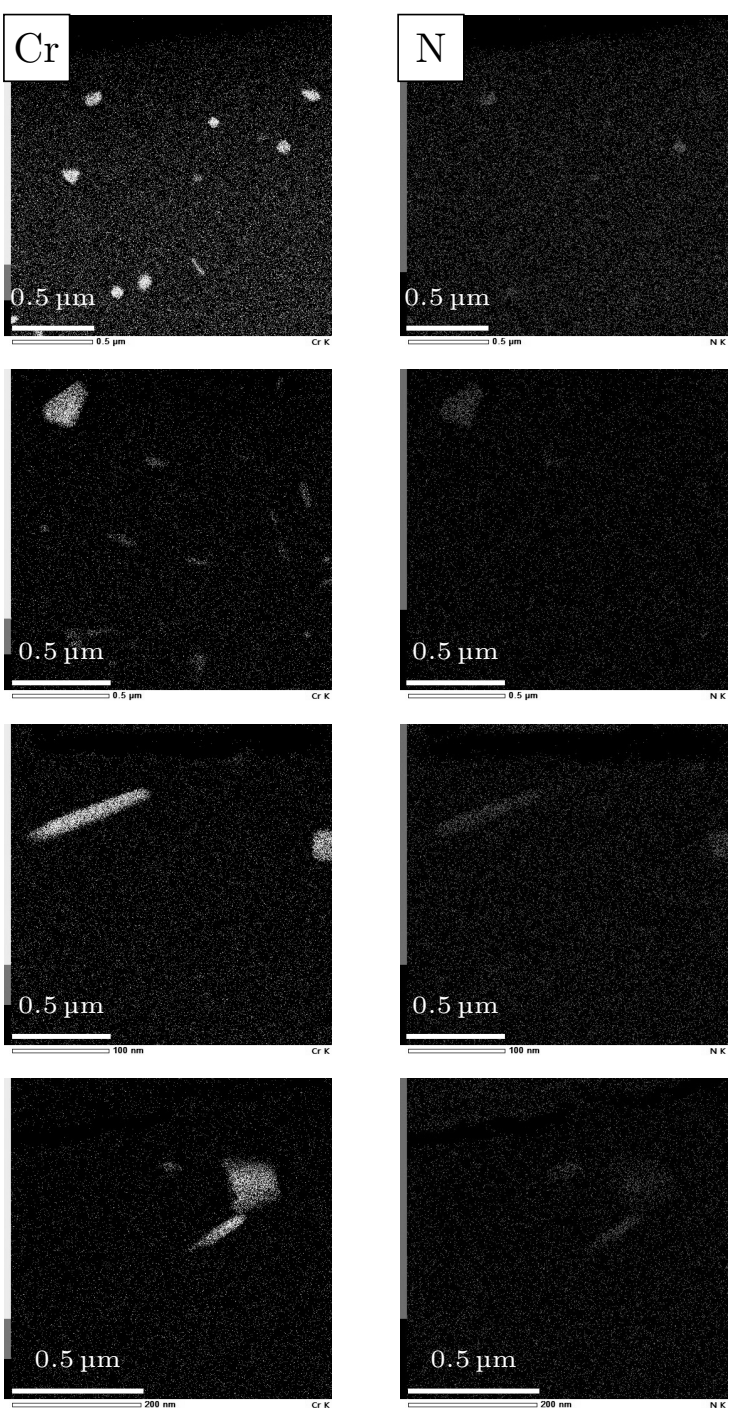

Figure 8: Energy dispersive x-ray maps of nitrides formed during nitriding of alloy $16 \mathrm{NiCrMo13}$. Nitrogen content around $0.25 \mathrm{wt} . \%$. analyses showed that a fine homogeneous dispersion of $\mathrm{Fe}_{16} \mathrm{~N}_{2}$ is responsible for such comportment. The presence of alloying elements is probably retarding the coherent to incoherent transformation of these precipitates, allowing such secondary hardening behavior at around $573 \mathrm{~K}$.

\section{Acknowledgments}

The authors are grateful to CNRS and IRT M2P for the financial support. We would also like to acknowledge the companies Safran, PSA Peugeot Citroën, Faurecia, ECM Technologies, Ascometal, Air Liquide, Airbus Helicopters, Arcelor Mittal, UTC Aerospace Systems and Poclain Hydraulics for the supply of raw materials and financial support through IRT M2P. Special thanks to Mrs. Christine Gendarme from Institut Jean Lamour for the conduction on chemical microanalyses.

\section{References}

[1] J. Slycke, T. Ericsson, A study of reactions occurring during the carbonitriding process, Journal of Heat Treatment 2 (1981) 319, doi:10.1007/BF02833069

[2] J. Slycke, T. Ericsson, A study of reactions occurring during the carbonitriding process part II, Journal of Heat Treatment 2 (1981) 97-112, doi:10.1007/BF02833226

[3] G. E. Totten (Ed.), Steel Heat Treatment: Metallurgy and Technologies, Taylor and Francis, 2006.

[4] A. G. Khachaturyan, Theory of Structural Transformations in Solids, Dover Publications, 1st edn., 1983.

[5] S. D. Catteau, S. Denis, J. Teixeira, J. Dulcy, M. Dehmas, A. Redjaïmia, M. Courteaux, Constituents effects of carbon and nitrogen on isothermal transformations of austenite in a low alloy steel, 21st Congress IFHTSE.

[6] S. Catteau, H. V. Landeghem, J. Teixeira, J. Dulcy, M. Dehmas, S. Denis, A. Redjaïmia, M. Courteaux, Carbon and nitrogen effects on microstructure and kinetics associated with bainitic transformation in a low-alloyed steel, Journal of Alloys and Compounds 658 (2016) 832 - 838, ISSN 0925-8388, doi: 10.1016/j.jallcom.2015.11.007

[7] G. Krauss, Martensite in steel: strength and structure, Materials Science and Engineering: A 273 - 275 (0) (1999) 40-57, ISSN 0921-5093, doi:10.1016/S0921-5093(99)00288-9 


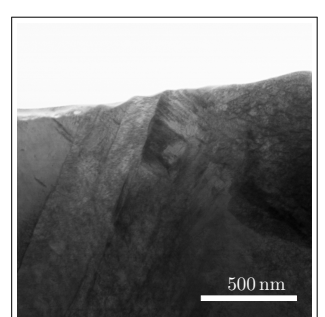

(a) STEM (BF) $\times 120 \mathrm{k}$

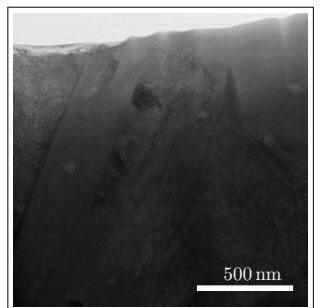

(b) STEM (BF) $\times 100 \mathrm{k}$

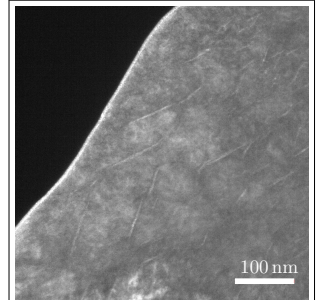

(c) TEM $(\mathrm{DF}) \times 150 \mathrm{k}$.

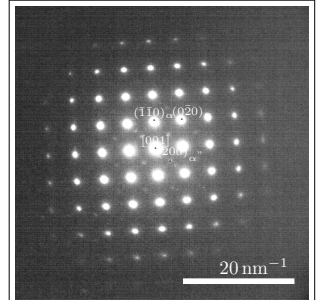

(d) TEM (DP).

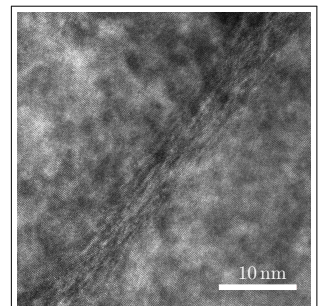

(e) HRTEM $\times 2$ M.

Figure 9: Micrographs of alloy $16 \mathrm{NiCrMo} 13$ nitrided, quenched and submitted to cryogenic treatment: (a) bright field (BF) showing the lath martensite structure, (b) high temperature MN-nitrides, (c) dark field (DF) oriented according to the reflexion indicated in the (d) diffraction pattern (DP) corresponding to the zone and (e) high resolution (HRTEM) detail of the $\mathrm{Fe}_{16} \mathrm{~N}_{2}$ zones.

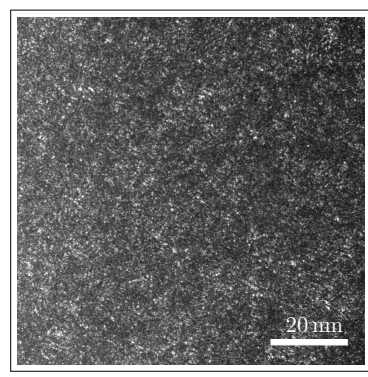

(a) HRTEM $\times 800 \mathrm{k}$.

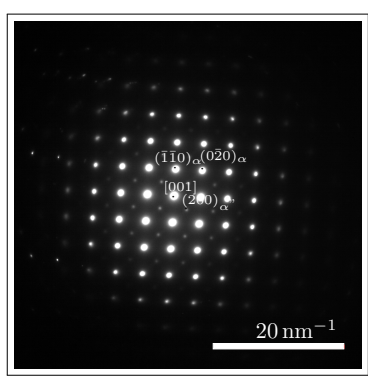

(b) TEM (DP).
Figure 10: Same sample as Fig. 9 but after tempering at $573 \mathrm{~K}$ : (a) high solution (HRTEM) detail of the $\mathrm{Fe}_{16} \mathrm{~N}_{2}$ nano-precipitates, (b) SAED oriented according to along $[001]_{\alpha}$.

[8] R. Kaplow, M. Ron, N. DeCristofaro, Mössbauer effect studies of tempered martensite, Metallurgical Transactions A 14 (6) (1983) 1135-1145, ISSN 0360-2133, doi:10.1007/ BF02670451

[9] A. Van Gent, F. Van Doorn, E. Mittemeijer, Crystallography and tempering behavior of iron-nitrogen martensite, Metallurgical Transactions A 16 (8) (1985) 1371-1384, ISSN 0360-2133, doi: 10.1007/BF02658670

[10] E. Mittemeijer, L. Cheng, P. van der Schaaf, C. Brakman, B. Korevaar, Analysis of nonisothermal transformation kinetics; tempering of iron-carbon and iron-nitrogen martensites, Metallurgical Transactions A 19 (4) (1988) 925-932, ISSN 0360-2133, doi:10.1007/BF02628377

[11] L. Cheng, E. Mittemeijer, The tempering of iron-nitrogen martensite; Dilatometric and calorimetric analysis, Metallurgical Transactions A 21 (1) (1990) 13-26, ISSN 0360-2133, doi: 10.1007/BF02656420

[12] L. Cheng, N. van der Pers, A. Böttger, T. de Keijser, E. Mittemeijer, Lattice changes of iron-nitrogen martensite on aging at room temperature, Metallurgical Transactions A 21 (11) (1990) 2857-2867, ISSN 0360-2133, doi:10.1007/BF02647206

[13] I. Fall, J.-M. Genin, Mössbauer spectroscopy study of the aging and tempering of high nitrogen quenched $\mathrm{Fe}-\mathrm{N}$ alloys: Kinetics of formation of $\mathrm{Fe}_{1} 6 \mathrm{~N}_{2}$ nitride by interstitial ordering in martensite, Metallurgical and Materials Transactions A 27 (8) (1996) 2160-2177, ISSN 1073-5623, doi:10.1007/BF02651871

[14] M. Van Genderen, A. Böttger, E. Mittemeijer, Formation of $\alpha^{\prime \prime}$ iron nitride in FeN martensite: Nitrogen vacancies, iron-atom displacements, and misfit-strain energy, Metallurgical and Ma- terials Transactions A 28 (1) (1997) 63-77, ISSN 1073-5623, doi:10.1007/s11661-997-0083-9

[15] O. D. Sherby, J. Wadsworth, D. R. Lesuer, C. K. Syn, Revisiting the Structure of Martensite in Iron-Carbon Steels, Materials Transactions 49 (9) (2008) 2016-2027, doi:10.2320/matertrans. MRA2007338

[16] M. Cohen, Strengthening Mechanisms in Steel, Materials Transactions 9 (Suppl.).

[17] L.-A. Norstrom, On the yield strength of quenched low-carbon martensite, Scandinavian Journal of Metallurgy 5 (1976) 159165.

[18] B. Hutchinson, J. Hagström, O. Karlsson, D. Lindell, M. Tornberg, F. Lindberg, M. Thuvander, Microstructures and hardness of as-quenched martensites $(0.1-0.5 \% \mathrm{C})$, Acta Materialia 59 (14) (2011) 5845 - 5858, ISSN 1359-6454, doi:10.1016/j. actamat.2011.05.061

[19] G. Ghosh, G. Olson, Simulation of paraequilibrium growth in multicomponent systems, Metallurgical and Materials Transactions A 32 (3) (2001) 455-467, ISSN 1073-5623, doi:10.1007/ s11661-001-0062-5

[20] L. Sproge, J. Ägren, Experimental and theoretical studies of gas consumption in the gas carburizing process, Journal of Heat Treating 6 (1) (1988) 9-19, ISSN 0190-9177, doi:10.1007/ BF02833160

[21] J.-O. Andersson, T. Helander, L. Höglund, P. Shi, B. Sundman, Thermo-Calc \& Dictra, Computational Tools for Materials Science, CALPHAD 26 (2) (2002) 273-312, doi:10.1016/ S0364-5916(02)00037-8

[22] A. Borgenstam, A. Engström, L. Höglund, J. A. gren, DICTRA, a Tool for Simulation of Diffusional Transformations in Alloys, Journal of Phase Equilibria 21 (3) (2000) 269-280, doi:10.1361/ 105497100770340057

[23] Y. hui Yang, M. qiu Wang, J. chao Chen, H. Dong, Microstructure and Mechanical Properties of Gear Steels After High Temperature Carburization, Journal of Iron and Steel Research, International 20 (12) (2013) 140 - 145, ISSN 1006-706X, doi: 10.1016/S1006-706X(13)60227-7

[24] J. Dulcy, M. Gantois, Théorie des traitements thermochimiques - Cémentation. Carburation., Techniques de l'ingénieur Traitements thermiques superficiels et thermochimiques base documentaire : TIB501DUO. (ref. article : m1222).

[25] E. Leher, Über das Eisen-Wasserstoff- AmmoniakGleichgewicht, Zeitschrift für Elektrochemie 36 (1930) 383-392.

[26] C. Chatfield, M. Hillert, A thermodynamical analysis of the FeMo-c system between 973 and 1273k, Calphad 1 (3) (1977) 201 - 223, ISSN 0364-5916, doi:10.1016/0364-5916(77)90001-3

[27] M. Hillert, M. Waldenström, Isothermal sections of the Fe-Mn- 
C system in the temperature range 873K-1373K, Calphad 1 (2) (1977) 97 - 132, ISSN 0364-5916, doi:10.1016/0364-5916(77) 90013-X

[28] M. Hillert, C. Qiu, A thermodynamic assessment of the FeCr-Ni-C system, Metallurgical Transactions A 22 (10) (1991) 2187-2198, ISSN 1543-1940, doi:10.1007/BF02664985

[29] F. Weitzer, J. Schuster, Phase diagrams of the ternary systems $\mathrm{Mn}, \mathrm{Fe}, \mathrm{Co}$, Ni-Si-N, Journal of Solid State Chemistry 70 (2) (1987) 178 - 184, ISSN 0022-4596, doi:10.1016/ 0022-4596(87)90054-5

[30] H. K. D. H. Bhadeshia, Carbon-carbon interactions in iron, Journal of Materials Science 39 (2004) 3949-3955, doi:10.1023/B: JMSC.0000031476.21217.fa

[31] K. Oda, H. Fujimura, H. Ino, Local interactions in carboncarbon and carbon-M (M: Al, Mn, Ni) atomic pairs in FCC $\gamma$ iron, Journal of Physics: Condensed Matter 6 (3) (1994) 679 , doi: 10.1088/0953-8984/6/3/008

[32] A. Sozinov, A. Balanyuk, V. Gavriljuk, C-C interaction in ironbase austenite and interpretation of Mössbauer spectra, Acta Materialia 45 (1) (1997) 225 - 232, ISSN 1359-6454, doi: 10.1016/S1359-6454(96)00138-3

[33] A. Sozinov, A. Balanyuk, V. Gavriljuk, N-N interaction and nitrogen activity in the iron base austenite, Acta Materialia 47 (3) (1999) 927 - 935, ISSN 1359-6454, doi:10.1016/ S1359-6454(98)00394-2

[34] L. Onsager, Reciprocal relations in irreversible processes. I., Physical Review 37 (1931) 405-426.

[35] L. Onsager, Reciprocal relations in irreversible processes. II., Physical Review 38 (1931) 2265-2279.

[36] J. Crank, P. Nicolson, A practical method for Numerical evaluation of solutions of partial differential equations of the heatconduction type, Advances in Computational Mathematics 6 (1996) 207-226, doi:10.1017/S0305004100023197 reprinted from Proc. Camb. Phil. Soc. 43 (1947) 50-67.

[37] R. Grange, C. Hribal, L. Porter, Hardness of tempered martensite in carbon and low-alloy steels, Metallurgical Transactions A 8 (11) (1977) 1775-1785, ISSN 0360-2133, doi:10.1007/ BF02646882

[38] P. Ferro, F. Bonollo, Modelling of the carburizing and quenching process applied to caterpillar track bushings, Modelling and Simulation in Materials Science and Engineering 22 (2) (2014) 025019, doi:10.1088/0965-0393/22/2/025019

[39] P. Haasen, Chapter 23 - Mechanical Properties of Solid Solutions, in: R. W. C. Haasen (Ed.), Physical Metallurgy (Fourth Edition), North-Holland, Oxford, fourth edition edn., ISBN 9780-444-89875-3, 2009 - 2073, doi:10.1016/B978-044489875-3/ 50028-4 1996.

[40] S. Morito, J. Nishikawa, T. Maki, Dislocation Density within Lath Martensite in $\mathrm{Fe}-\mathrm{C}$ and $\mathrm{Fe}-\mathrm{Ni}$ Alloys, ISIJ International 43 (9) (2003) 1475-1477, doi:10.2355/isijinternational. 43.1475

[41] M.-S. Yahia, Contribution à l'étude de l'influence de l'azote dans les traitements thermochimiques de surface des aciers en phase austenitique, Ph.D. thesis, Institut National Polytechnique de Lorraine, 1995.

[42] E. J. Mittemeijer, Fundamentals of Materials Science: the microstructure-property relationship using metals as model systems, Springer, doi:10.1007/978-3-642-10500-5. 2011.

[43] N. Wan, W. Xiong, J. Suo, Mathematical Model for Tempering Time Effect on Quenched Steel Based on Hollomon Parameter, Journal of Materials Sciences and Technology 21 (06) 803. 